\title{
Relatórios
}

\section{RELATÓRIO DA COMISSÃO DE LEGISLAÇAO 1972/73}

\author{
Maria Alves Amorim*
}

Reuniões e comunicações -

Comparecemos a 4 das 5 reuniões da Diretoria.

Mantivemos comunicações telefônicas frequentes com a Diretoria, para informações dos trabalhos da Comissão.

Recebemos orientações e informações da Diretoria enviadas Sra. Presidente e Secretária Executiva - boletins, convocações pra reuniões, ofício a serem entregues.

Trabalhos realizados:

1.) Recebemos da Secretária Executiva, informações da existência de uma Portaria do MTPS onde a enfermeira não estava incluida no Quadro de Enfermagem.

Solicitamos à Biblioteca da Câmara que pesquisasse. Encontrada a Portaria n.o 3.237 de 2/8/72.

Com Izaura Godoy, entramos em contato com o MTPS. Fomos encaminhadas ao Dr. Gilson Viana, Secretário do Trabalho que nos recebeu e nos orientou da E.M. que a Diretoria da ABEn deveria enviar ao Sr. Ministro Julio Barata. Telefonamos à Dr.a Glete de Aicântara, informando.

Recebemos o ofício S.P. $36 / 72$ solicitando alteração da referida Fortaria, a fim de que o enfermeiro seja incluido no grupo de profisisonais especializados do Serviço de Higiene e Medicina do Trabalho.

2.0) Recebemos da Sr. ${ }^{\text {a }}$ Presidente o Of. S.P. n.o $40 / 72$ dirigido ao Sr. Ministro do Trabalho, solicitando providências no sentido de revogar a Portaria Ministerial n. ${ }^{\circ}$ SPS-80 (BS/DS/69, de 4/3/72)

* Coordenadora da Comissão da Legislação. 
que inclue como segurados autonomos ou auxiliares de Enfermagem e atendentes de Enfermagem em face de seu desacordo com a legislação do exercício da enfermagem. (MTPS - 329.636/72).

3..$^{\circ}$ Acompanhamos a tramitação do Projeto de Lei n.0 294/71 de autoria do Dep. Alpheu Gasparini, que regula o ensino da enfermagem no Brasil.

Levamos à Diretoria o substitutivo ao referido Projeto, em reunião realizada no dia 2/12/72 em $\mathbf{S}$. Paulo.

Pronto para ordem do dia.

Entregue à Diretoria da ABEn a matéria aprovada nas comissões, em 30/6/73.

4. ${ }^{\circ}$ Projeto de Lei n.o 2.334/70 - Dep. Emilio Gomes - acrescenta dispositivo à Lei n.o 2.604/55 e dá outras providências, definindo as atribuições do técnico de Enfermagem.

Pronto para ordem do dia.

Entregue à Diretoria da ABEn a matéria aprovada nas Comissões da Câmara, em 30/6/73.

5.0) Em reunião da Diretoria, realizada em $14 / 8 / 72$, ao tomarmos posse dos trabalhos desta Comissão recebemos as Recomendações e Propostas aprovadas pela Assembléia de Delegados: B.H. Que os enfermeiros nos estados criassem imediatamente a Associação Profissional de Enfermeiros para criar sindicatos, uma vez que a criação dos Conselhos de Enfermagem estava dependendo da formação de sindicatos. Com a mudança do Secretário Geral do MTPS - marcamos audiência com o novo Secretário Dr. Ayrton Aché Pillar. Estivemos com a Dr. ${ }^{a}$ Haydée Dourado e informamos das dificuldades em criarmos os Conselhos de Enfermagem. Fomos muito bem recebidas e encaminhadas aos assessores: Dr. Waldyr Menezes e Dr. Renato.

Em 20/8/72 - Com a Dr. ${ }^{a}$ Haydée Dourado, participamos do estudo da E.M. que encaminhamos à Diretoria em 24/8/72.

27/9 - Recebemos of. S.P. n. ${ }^{\circ}$ 35/72 de 21/9/72 - Proposta da $A B E n$, de alterações ao Projeto de Lei que dispõe sobre a criação dos Conselhos de Enfermagem e dá outras providências.

Voltou ao MTPS, do Palácio do Planalto onde aguardava E.M. dà ABEn.

Com D. Izaura, fomos várias vezes ao MTPS, trabalhando junto aos Assessores: Dr. Waldyr Menezes e Dr. Renato.

De volta ao Palácio do Planalto mantivemos comunicação permanente com o Dr. Fernando Silva. 
6.0) Dispensa de ponto do XV Congresso do Conselho Internacional de Enfermagem de 13 a 19/5/73 no México — PR 002012/73 E.M. 63/73 do M.S.

Publicado no Diário Oficial de 25/4/73.

7.0) Dispensa de ponto do CEBEn João Pessoa - Pb. PR . 000939/73.

Publicado no D.O. de 31/5/73.

8. P) Pela passagem de ano, recebemos da colega Zuleika B. Esteves, da GB um cartão de felicitações e informação que é a coordenadora da C.L. GB., pondo-se à disposição desta C.L. para acompanhar tramitação de processos. Pedimos para acompanhar a tramitação dos Processos do MTPS e que se encontram no Gabinete do Ministro na GB.

9.0) Recebemos comunicação da Secretária Executiva, com trechos do trabalho apresentado no Congresso da UNAE em Belém. Levamos à Diretoria - em reunião - a Comissão de Educação estudará 0 assunto.

Em 26/3/73 foi encaminhada ao Congresso Nacional a Mensagem 48/73 do Poder Executivo e que, na Câmara recebeu o n. ${ }^{\circ} 1.126$. Esteve na Pauta da Ordem do Dia, durante 5 dias, para receber emendas em Plenário. Distribuido as comissões de: Constituição e Justiça, Legislação Social e Saúde.

Com a Dr. ${ }^{\text {a }}$ Haydée fomos recebidas pelos Presidentes das referidas comissões: Dep. Lauro Leitão (C. Justiça) Dep. Cid Furtado (C. Legislação) Dep. Jaison Barreto (C. Saúde). Solicitamos que o Projeto fosse aprovado na íntegra.

Audiência com Lider e Vice-Lider do Governo na Câmara Dep. Geraldo Freire e Dep. Cantidio Sampaio - respectivamente. Fomos informadas de que, como Mensagem do P. Executivo, não deveria receber emendas.

Porém, um grupo de Deputados: Alpheu Gasparini (SP) Célio Marques Fernandes (RS) Helio Helbert dos Santos (RS) (relator da Comissão de Saúde) foi ao Sr. Ministro do Trabalho, defendendo os interesses da UNAE, solicitar autorização para apresentarr emendas ao Projeto, colocando representação das demais categorias de enfermagem no Conselho Federal art. 5., assim como havia nos Conselhos Regionais, art. 11.'.

Foram apresentadas várias outras emendas, nas comissões. Ver avulso n.o $1.126 \mathrm{~A}$ - Porém, em Plenário, só foram aprovadas as referentes ao art. 5..$^{\circ}$ e 11.0. Ver avulso 0/73 do D. Federal.

Várias colegas de Brasília trabalharam conosco junto aos Srs. Deputados, informando sobre a legislação do ensino e do exercício 
da enfermagem - Myriam Generoso, Maria Francisca Rangel, Terezinha do Valle, Lydia Matta, Izaura Godoy, Clélia Marcia Cordova, Luiz Aragão, Ivalda e outras.

De S. Paulo veio a Presidente da Seção de S. Paulo - Dra. Circe Melo Ribeiro, que teve audiências com o Lider e Vice-Lider do Governo, e vários Deputados da Liderança da Arena e Presidente das Comissões.

Posteriormente, esteve conosco, a Sra. Presidente, Dr.a Glete de Alcântara, que foi recebida pelo Sr. Ministro do Trabalho em com: panhia do Sr. Deputado Aldo Lupo e Lydia Matta.

Recebida pelo Lider do Governo, Dep. Geraldo Freire e por vários Deputados: Dep. Faria Lima colocou-se à nossa disposição, informando das providências a serem tomadas, como propor E.M. e encaminhar a colaboração no sentido de manter o texto original dos artigos $5 .^{\circ}$ e $11 .^{\circ}$ do Projeto

Recebemos o material elaborado pela Diretoria da ABEn, em S. Paulo, e distribuimos a todos os Deputados e Senadores e dos Conselhos Federais que estão em Brasília.

Fizemos várias tentativas para confirmar audiência com o Chefe da Casa Civil - Ministro Leitão de Abreu.

Por intermédio de um dos Assessores legislativos do Senado Federal, soubemos que, no Palácio do Planalto já conheciam nossas reinvindicações portanto, não seria necessário nos receber.

No Senado Federal, trabalhamos em condições mais favoráveis com a participação das colegas: Dalva Bastos (S.F.) Terezinha do Valle (RS) Vani Faraon, Catarina Pillar, Maria Helena Neri (Diretora da EERS).

Inicialmente preparamos a E.M. em torno da Mensagem 48/73, com a colega Vani Faraon e Ilse Maria Silveira. O trabalho mostra a inconveniência da participação dos profisisonais de enfermagem não portadores de diploma de nível superior, para os interesses da organização e disciplina profissisonal, contrariam a legislação do cxercício da profissão, Lei n. ${ }^{\circ}$ 2.604/55, na qual os auxiliares de enfermagem, enfermeiros práticos e práticos de enfermagem devem ciesempenhar as atividades profissionais "sempre sob orientação do médico ou de enfermeiro".

Assim sendo, como admitir que possam participar da supervisão superior das atividades éticas e profissionais do enfermeiro?

Como poderão nos colegiados dos Conselhos, opinar e ajuizar sobre o acerto de conduta profisisonal ou ética do enfermeiro?

O que seria um indiscutível subversão na ordem hierarquica natural. 
Aliás, é do sistema brasileiro que, nos processos disciplinares e nas organizaçōes de comando, se respeite o princípio da hierarquia, que possue na graduação uma de suas expressões. Assim como, por exemplo, num inquérito administrativo não pode participar sequer da respectiva comissão processante, funcionário de hierarquia inferior à do acusado. Parece evidente, segundo a própria natureza das coisas, que não cabe, na direção de órgão de disciplina profissional, como são os conselhos, participar exercente dessas atividades, de rivel inferior. Isso, aliás, é o que sucede com todas as leỉs do Brasil, que regulam as profissões.

Após essas ponderações, apresentamos sugestões de emendas:

Emenda n.o 1 - (art. 5..$^{\circ}$ ).

Restabelecimento da redação constante do Projeto do Poder Executivo - Mensagem n.o 48/73 (aprovada).

Emenda n. ${ }^{\circ} 2$ -

Inclua-se no art. $60^{\circ}$ o seguinte - parágrafo único:

"Parágrafo único - na organização dos quadros distintos para incrição de profissionais, o Conselho Federal de Enfermagem adotará como critério o disposto na Lei 2.604/55, no que couber" (aprorada).

\section{Emenda n.o 3 - (Art. 11.0)}

Restabelecer a redação do projeto primitivo, introduzindo-lhe, ainda a modificação que prevê requisito de formação técnica, a ser preenchida pelos representantes das demais categorias de enfermagem na Direção dos Conselhos Regionais, ao lado dos enfermeiros. (rejeitada na Comissão de Constituição e Justiça do Senado Federal, por ser injurídica).

Emenda n.o 4 -

Inclua-se no art. 18 o parágrafo $3 .^{\circ}$ com a seguinte redação:

Par. $3 .^{\circ}$ - no julgamento das infrações atribuidas a enfermeiro, o quorum respectivo nos Conselhos Regionais será constituido, exclusivamente, por profissionais previstos no art. 11, inciso I (enfermeiro) - emenda rejeitada na C.C. Justiça do S.F. por injuridicidade.

Todos os membros do Conselho tem os mesmos direitos e deveres. Durante a tramitação do referido Projeto no S. Federa!, trabalhamos intensamente (manhã, tarde e noite) com as colegas: Dalva Bastos, do Senado, Terezinha no Valle, INPS. E, com as colegas: Vani Faraon, Catarina Pilar, Deborah e Maria Helena Neri, do R.S. 
No dia 8/5/73 - c/Vani aguardavamos audiência com Sen. Petronio Portella, e tivemos o prazer de receber Ir. Tereza, Ermeline Boing e Dalva Bastos.

Nas comissões de Saúde e Legislação Social, foram aprovadas emendas, no sentido de que a representação das demais categorias de enfermagem, fosse de nível médio, tanto no COFEn como nos coREns.

Em plenário do S.F. foram apresentadas emendas dos atendentes pelo Sen. Nelson Carneiro, e das enfermeiras, pelo Sen. Virgílio Tavora, com autorização do Chefe da Casa Civil, através das colega.s do R.S.

Recebendo emendas no Plenário, voltou às Comissões inclusive à C. Justiça do S. Federa!. No S. Federal, havia sido restabelecido - Projeto original; porém, como voltaria à Camara de Deputados houve acordo entre as duas Casas, modificando na Redação final do Senado, o art. $11 .^{\circ}$ que voltou a ter a representação de 5 para as demais categorias. Na C.D. foram aprovadas as emendas do $\mathbf{S}$. Federal. 